\title{
Idea Vilariño y Mario Benedetti: crónica de un libro inconcluso
}

\section{Oscar Brando}

Facultad de la Cultura de la Universidad de Centro Latinoamericano de Economía Humana (CLAEH), Uruguay

Recibido: diciembre 2020 Aceptado: abril 2021

\begin{abstract}
Resumen
De las circunstancias en las que coincidieron los trabajos y los días de Idea Vilariño y Mario Benedetti, este texto recorta una de los años ochenta e intenta, a partir de ella, trazar algunos círculos concéntricos en torno a las concepciones sobre la poesía, las poéticas y la tarea crítica.
\end{abstract}

PALABRAS CLAVE: trabajo crítico, poéticas, poesía, ritmo, sencillez.

Idea Vilariño and Mario Benedetti: chronicle of an unfinished book

\begin{abstract}
From the circumstances in which the works and days of Idea Vilariño and Mario Benedetti concurred, this text focuses on the eighties and, from that basis, aims to draw some concentric circles around the notions of poetry, poetics and the critical task.
\end{abstract}

KEYWORDS: critical work, poetics, poetry, rhythm, simplicity.

\section{Idea Vilariño e Mario Benedetti: crônica de um livro inacabado}

\section{Resumo}

A partir das circunstâncias em que coincidiram as obras e os dias de Idea Vilariño e Mario Benedetti, o texto recorta uma dos anos oitenta e tenta, a partir dela, traçar alguns círculos concêntricos em torno das concepções da poesia, da poética e da tarefa crítica. 
PALAVRAS-CHAVE: obra crítica, poética, poesia, ritmo, simplicidade.

\section{Introducción}

El 13 de abril de 1983, a punto de trasladarse de Palma de Mallorca a Madrid, Benedetti le envió una carta a Idea Vilariño comentándole la mudanza y contándole que había recibido, hacía unos días, una invitación de Amos Segala para participar en el proyecto de Archivos de la Unesco que recién se echaba a andar. ${ }^{1}$ Benedetti le informó a Idea que habían sido seleccionados cincuenta autores ya muertos y que por el momento habían elegido tres uruguayos: Amorim, Quiroga y Rodó, pero que a él le habían ofrecido encargarse del volumen que se ocuparía de la obra del poeta argentino Baldomero Fernández Moreno. La invitó a colaborar en dicha obra. Queda en mi penumbra por qué Segala le ofreció a Benedetti trabajar sobre Fernández Moreno, ya que no me consta que hubiera una relación estrecha entre ambos. Sin exagerar las especulaciones, se puede sospechar que Segala conocía la obra del uruguayo y advertía el parentesco, que en varias oportunidades el propio Benedetti había subrayado, entre su poesía y la del argentino; o que César Fernández Moreno, hijo de Baldomero, radicado en París y vinculado con la Unesco, había recomendado a Benedetti con quien tenía un trato de mayor proximidad. En carta de Benedetti a Idea del 6 de agosto de 1984, cuando ya esta había aceptado la invitación a escribir y estaban ajustando criterios de extensión, Benedetti le comentaba la "mucha relación" que César Fernández Moreno tenía con Amos Segala.

Desde el principio Benedetti entendió que el trabajo sobre Fernández Moreno era "algo así como pagar una deuda"; no había escrito, hasta ese momento, ningún ensayo sobre el admirado escritor. Al mismo tiempo recelaba del interés que Idea Vilariño pudiese tener por el poeta argentino. Le expresó la duda y, para alentar la aceptación, le argumentó que "sería formidable, por ejemplo, que usted hiciera un trabajo sobre ritmos o sobre otro tema que le gustara enfocar". A continuación y sin pausa esgrimió un segundo argumento: la tarea sería remunerada en dólares $\mathrm{y}$, aunque en ese momento no supiese el monto, podía presumir que no debía ser poco tratándose de tarifas de la Unesco. En la ya citada carta del 6 de agosto de 1984 Benedetti le iba a confirmar que el monto ascendería a 500 dólares. No voy a entrar aquí en el terreno minado del trabajo intelectual y su remuneración. Requeriría, para los personajes de este drama, remontarnos a su juventud, a su desmesurada capacidad y voluntad de trabajo, a los emprendimientos culturales, revistas y editoriales, en los que fueron articulando los distintos modos de profesionalismo que echaron a andar. Cuando se trató de Número, la revista y la editorial, en las que ambos coincidieron durante años (1950-1956), la ecuación económica no quería garantizar un medio de vida sino la sustentabilidad que permitiera llevar adelante algunas ideas sobre la cultura. La docencia o la atención en la Biblioteca Pedagógica eran, para Idea Vilariño, tareas intelectuales con las que se ganaba la vida. En el caso de Benedetti el trabajo como empleado de la empresa inmobiliaria Piria fue ajeno a todo quehacer cultural (aunque Piria, anunciador de Número, asistiera para la supervivencia de la revista). Sus años de periodismo en el diario La Mañana, 1960-1965, los realizó con absoluto profesionalismo en un medio cuya línea directriz era totalmente ajena a sus ideas. La ocasión que estamos analizando, año 1983, encontraba a Benedetti en una mudanza más de sus exilios y a Idea Vilariño en Uruguay, destituida de la enseñanza y buscando sobrevivir con publicaciones

1 Una curiosidad: los documentos “oficiales” en los que Amos Segala hizo luego la historia de los Archivos dicen que la primera reunión operativa de los participantes del proyecto se realizó en mayo de 1983, en París. Según recordó Segala en más de una oportunidad, allí se definieron criterios y autores. De manera que la carta de Benedetti hablaría de un madrugar a esa instancia, de un pequeño desajuste entre los preparativos prácticos y los eventos institucionales. 
para estudiantes y docentes, con traducciones y otros encargos. Como punto de referencia podríamos tomar la publicación de la obra de Julio Herrera y Reissig Poesía completa y prosa selecta que, hacia fines de los años setenta, había realizado por pedido de la editorial Ayacucho de Caracas que dirigía a la sazón Ángel Rama. El énfasis en lo económico no era trivial ya que resultaba la oportunidad de obtener algún rédito del trabajo intelectual -tantas veces hecho gratuitamente- en una situación de emergencia: la de una profesora separada de su cargo por los gobiernos cívico-militares. ${ }^{2}$

\section{Idea Vilariño: ciencia, números, poesía}

En relación a los trabajos críticos de Idea Vilariño, Benedetti sufría un leve error de apreciación. En la carta del 6 de agosto de 1984 en la que inauguraba el tuteo, Benedetti insistía en que podía realizar con Fernández Moreno el tipo de trabajo que había hecho con Antonio Machado. Seguramente Benedetti traía a su memoria el artículo sobre grupos simétricos en la poesía de Machado que Vilariño había adelantado en la revista Número 15-16-17, julio-diciembre de 1951, como parte de un trabajo mayor, Grupos simétricos en poesía, que publicaría en 1958. La sugerencia de Benedetti, que intentaba imprimir entusiasmo a una tarea que podía sospechar desganada, parecía entender que el método practicado por Vilariño en la poesía de Machado y en otros casos prescindía del rapport que la crítica podía tener con la obra sobre la que operaba. Los estudios científicos, "geométricos" del rumano francés Pius Servien que Idea había leído y aplicado al estudio de los ritmos poéticos de algunos autores disimulaban la necesidad de afinidad con la poesía o el poeta estudiados. No me siento autorizado para decir qué hacía Pius Servien con su sistema crítico si no es por los breves fragmentos que copia Idea Vilariño en su trabajo "Una ciencia de la poesía: Pius Servien y los ritmos" (2018: 237). Allí aparecen ejemplos de su método aplicado a la lírica griega de Píndaro o Esquilo. Puedo afirmar que desde el principio Idea Vilariño trabajó sobre la poesía de poetas que ya consideraba valiosos. En el cierre del libro La masa sonora del poema, que había preparado para ser publicado a mediados de los años noventa por el Instituto del Libro y que finalmente, inédito en vida de Idea, sería póstumamente editado por Ignacio Bajter para la Biblioteca Nacional, Idea hacía la siguiente consideración: "Hace décadas que me ocupo de estos problemas de prosodia y que aplico mi método de análisis de la masa vocálica del poema a grandes poetas de nuestra lengua; a los aquí estudiados (Machado, Darío, J. A. Silva) y a Julio Herrera y Reissig, a Bécquer, a García Lorca entre otros" (Vilariño, 2016: 112).

Entre los numerosos aciertos y sutilezas que tiene el trabajo de Ignacio Bajter (2014) acerca del método de Idea para el análisis de poesía, se pueden citar la filiación torresgarciana que lee a través de Carlos Real de Azúa, las relaciones con los trabajos musicológicos de Lauro Ayestarán y de prosodia de Carlos Vaz Ferreira, una observación sobre el nombre de las revistas de la generación que merecería una ampliación, etcétera, así como el de la relación epocal con el ensayo de Real de Azúa conocido con el título de "Conocimiento y goce". Se trata, tal vez, del único trabajo de cierta extensión que queda inédito en su archivo. Escrito en el verano de 1960, supuso la acumulación de un razonamiento sobre cuestiones de estética que habían sido procesadas en el mismo tiempo en que Vilariño afinaba su método piuserviano. Sin pretender en este momento ir mucho más allá de lo

2 Ver las cartas intercambiadas entre Idea Vilariño y Ángel Rama a propósito del trabajo sobre Julio Herrera para Ayacucho (2014: 223-227). El tema desborda el recluido enfoque de este trabajo. Con más espacio se debería explayar la relación entre ética y trabajo intelectual que acechó sin pausa a nuestros protagonistas. El complicado nudo de los concursos literarios o asuntos como la decisión de no presentarse a la beca Guggenheim, acerca de la que Idea Vilariño consultó a Benedetti en 1982, abrirían capítulos en la cuestión. 
que el título sugiere, el trabajo de Real de Azúa se adscribía a la convicción de que, en tanto emoción y razón no estaban enemistadas, el conocimiento aumentaba la capacidad de disfrutar un texto literario.

En cuanto a la tarea de creación, muchos artistas, teóricos y críticos literarios habían procedido explicando lo formal al servicio de la sintaxis o de los campos semánticos. La conocida "filosofía de la composición" de Poe proponía correlatos entre un tema, la índole de su emoción y los sonidos que los podían encarnar. Yuri Lotman veía las regularidades y las repeticiones como mecanismos de saturación semántica; Idea Vilariño quiso ir más allá, su posición fue más radical: "Pero nuestras indagaciones son ajenas a los significados y a su relación con los sonidos y con su organización" escribió en La masa sonora... "Atienden solo a esa sustancia fónica articulada, no funcional, de la que se ocupa la fonética y no la fonología. Y, dentro de ella, como es lo más corriente en este tipo de asedios, más precisamente a las vocales" (Vilariño, 2016: 17).

Idea no siempre se aventuraba a afirmar que las elecciones de sonidos y acentuaciones, la organización de grupos rítmicos hechas por el artista fuesen voluntarias: eso exigía el estudio de originales y manuscritos. Pero cuando se proponía acometer un estudio de selección y ordenamiento de las masas vocálicas o hacer especulaciones rítmicas y musicales sobre un poema o un grupo de ellos era porque ya había una previa valoración que el estudio confirmaba. El poeta podía sostener su obra sobre simetrías vocálicas o regularidades acentuales con aparente involuntariedad; mostrar gran inocencia frente al hecho y presentarlo como suma sencillez (era el caso de Antonio Machado), pero nada de eso borraba que en el inconsciente del texto o en la conciencia poética del autor ("prodigioso don", "oído de poeta" decía Idea para el caso de Machado) habitaba la habilidad de organización.

Consta con claridad que a la altura de 1952 Vilariño había leído y asimilado con rigor y gusto el estudio de los ritmos propuesto en los libros de Pius Servien. Ese año, en la revista Número 20 de julio-setiembre, hizo una cuidadosa síntesis del método Servien. Antes de esa fecha Idea había realizado críticas de poesía en forma de rápida reseña bibliográfica o, en algún caso, con mayor morosidad. Entre estas se destacaron su colaboración en el primer número de la revista Clinamen de 1947 sobre la poesía de Juan Parra del Riego, y el extenso y muy apreciable ensayo de lectura que aplicó a la obra de Julio Herrera y Reissig para la entrega especial de la revista Número 6-78,1950 , dedicada a homenajear a la generación del 900 . Se podría agregar, si nos detuviéramos en preocupaciones de largo aliento (lo fueron los dos casos citados), la atención que tuvo por la poesía de Humberto Megget, muerto muy joven en 1951; Idea se ocupó rápidamente de él reuniendo en 1952 una treintena larga de poemas que había dejado inéditos y lo reeditó en versión ampliada en $1965 .^{3}$

A los trabajos sobre Parra y Herrera, con ser el resultado de una lectura inmanente y de tipo formal, no sería fácil definirlos como herederos del método del rumano francés. El estudio de los grupos vocálicos en la poesía de Machado, adelantado en 1951, sintonizaba con otros que Idea reuniría en Grupos simétricos (1958) y en La Masa sonora del poema (1986-2016): estos sí estaban emparentados con el modelo que Servien le había acercado. Bajter (Vilariño, 2016: 5) recuerda la publicación de los

\footnotetext{
3 De nuevo, un tema que abriría este artículo a otros confines sería el de los poetas que murieron jóvenes: Jules Laforgue, Parra del Riego, Humberto Megget, Julio Herrera. Vilariño sintió un atractivo por observar qué hicieron y adivinar qué hubieran hecho de haber vivido más tiempo; por mirar la publicación escasa y discutir qué se podía agregar y con qué criterio. Se ocupó de ediciones póstumas de Megget y Parra del Riego, discutió la de Julio Herrera. De este dijo: “el mejor homenaje a rendírsele consistirá en juzgarlo solo por lo que él mismo eligió, en definitiva, o separar, entre lo que quedó fuera, con su misma exigencia” “JHyR seis años de poesía” en De la poesía y los poetas, 2018: 86). Esa preocupación no poca relación tuvo con su propia creación y con la organización de sus libros hasta la aprobación de su Poesía completa en 2002.
} 
poemas de Servien en 1942 que se hizo acompañada del ensayo de Paul Valéry "Le cas Servien". El libro pudo ser leído en Uruguay y los conceptos de Valéry fueron asimilados como parte de un pensar poético que tuvo en esos años gran prédica entre algunos jóvenes poetas de los años cuarenta. ¿Lo conoció Idea, lo tuvo en cuenta para procesar su propio método y generar su propio caso? Recién tendremos, hasta donde yo conozco, una mención al trabajo de Valéry sobre "le cas Servien" en el ya citado cierre de la versión definitiva de La masa sonora..., escrito a principios de los años noventa. Allí Idea rescató dos citas de "Le cas Servien" en las que Valéry insistía en la importancia de los elementos prosódicos y afirmaba que Pius Servien era el que, hasta ese momento, había hecho los trabajos más profundos sobre la cuestión del ritmo. Pero en el documento esencial para una pesquisa como esta, el Diario que Idea llevó a lo largo de su vida, no figura mención alguna en los tempranos años cuarenta. Admitamos que no todo figura en un Diario. El diarista puede no darse cuenta, en el estricto presente en que irrumpe el diario, de la importancia de un suceso, un pensamiento, una lectura. Y siempre es difícil agregarlo después, así el diario sea pasado en limpio como lo fue este de Idea. Lo que quedó escrito en la parte del Diario de juventud hasta ahora editada, que llega a 1945, no denuncia esa lectura de manera directa e, indirectamente, no es fácil deducir que ciertas observaciones sobre poesía provengan de la fuente Valéry-Servien. Los comentarios sobre poesía y en particular sobre la musicalidad y el ritmo en esta tienen otras fuentes: la escucha de la lectura en voz alta de su padre, los conceptos provistos por Emilio Oribe en sus disertaciones sobre estética. En 1943, la alusión más clara es la siguiente: "La poesía de veras no solo desnuda una idea poética diáfana, sino que lleva la forma, la despreciada forma, las palabras, los acentos, el ritmo, revistiendo esa idea, haciéndolo". Oribe escribe: "Un verso perfecto contiene en sí emoción infinita, aunque no exprese nada". Pero también: "Una palabra bella vendrá siempre con una idea en el pico". (Diario..., abril 18 de 1943, cursivas propias).

En cuanto a la parte aún inédita del diario (Bajter hace alguna alusión a ella) las menciones a Servien son muy escasas: en 1947 deja constancia de la lectura del libro Les Rythmes comme introduction physique a l'esthetique de Servien, más o menos al mismo tiempo en que se publica en al revista Clinamen su trabajo de análisis de los "Nocturnos" de Parra del Riego. Las otras menciones son muy tardías para lo que nos preocupa y además tuvieron otra finalidad: localizar, durante la estadía en París en 1954, a Queneau y a Servien, las dos únicas personas que le interesaba ver en esa ciudad (tomemos esta afirmación como parte de una obsesión y también como un desplante más).

\section{"La despreciada forma"}

"Entre los modernistas se encuentran nuestros últimos poetas sabios" escribió Idea Vilariño en su Conocimiento de Dario (1988: 80). Y enseguida: "Los críticos actuales que saben tanto más de tantas cosas, saben de prosodia mucho menos de lo que sabía cualquiera de nuestros poetas modernistas y hasta lo que sabía su público culto". A esa sabiduría musical que tanto cautivaba a los amantes de la poesía siguió, hacia 1920, la plaga del "versolibrismo", responsable, según Vilariño, de la retracción del público lector de poesía. He ahí, entonces, uno de los enemigos de la poesía: el vano desborde de líneas cortadas a capricho, sin estructura, y a veces sin intensidad ni lirismo. En el otro extremo se podía ubicar a los versificadores que, en el envase de la tradición poética, hacían versos y estrofas pero no poesía. Allí estaría el punto de partida de la crítica de Idea al desgastado soneto, a la rima mecánica, a la imagen desafortunada. La poesía enfrentaba, bajo su mirada, una ecuación difícil: no era posible volver al régimen del modernismo y la flexibilización que este había infligido a la lengua había operado como desestructuradora del orden verbal; se debía, entonces, reconocer y recuperar la cualidad lírica que distinguiera esta modalidad 
de otras formas de expresión. Los recursos repetitivos parecían los más adecuados y proclives a crear la estructura de reiteración sobre la que sostener el sentido poético. En el capítulo "La masa sonora del poema" del libro homónimo, Vilariño copió un párrafo de la Psicología del ritmo de Paul Fraisse:

La percepción del ritmo nace a la vez de la percepción de las estructuras y de su repetición. (...) La repetición engendra bien la satisfacción de la espera, bien el asombro de lo inesperado. La poesía somete la expresión a reglas que aseguran la satisfacción a anticipaciones confirmadas y que permiten la atracción de lo imprevisible sobre un fondo de regularidad y de repeticiones incesante. (2016: 20)

Los más conocidos y usados así como también desgastados y fosilizados medios de repetición eran la rima y el metro. Decía Idea que a pesar de no ser connaturales, rima y metro se habían transformado en una segunda naturaleza de la poesía occidental (2016: 20). Sin embargo podía haber poesía sin metro fijo, sin acentos fijos, sin rima, pero no podía haberla sin ritmo. Le era esencial (2016: 23). En una entrevista realizada en 1971, Mario Benedetti interrogaba a Idea acerca de su preocupación por los ritmos, qué significado tenía el ritmo en relación con el hecho poético. "¿Qué significado tiene el ritmo? -respondía Vilariño-. Es fundamental en todo hecho poético. En un poema puede faltar todo lo demás: hasta puede, en determinados juegos, faltar el sentido; nunca el ritmo. Es esencial: por él algo es o no lírico" (Benedetti, 1972: 254).

Para aclarar qué era el ritmo Idea acudía a Servien que lo llamaba "la puerta secreta de la poesía": "Todo objeto en que se reconozca un ritmo tiene una estructura numérica, una estructura que puede transcribirse en números, cuyos números obedecen siempre a una ley simple" (2016: 23). Así se formulaba la primera ley general de la estética que, sin llegar a identificar ritmo con belleza, permitía el ingreso a esta por el lado de las leyes físicas. La explicación de la belleza de todo ente rítmico era "del orden de las estructuras, de los números" decía Idea siguiendo a Servien (2018: 240). A partir de ese descubrimiento Idea se afanaba en circuir la base rítmica del poema y la encontraba en el grupo rítmico, ordenamiento de las unidades fonéticas mínimas, las sílabas, en torno a la vocal y su acento. Sería, entonces, sobre la base de esos grupos que Idea Vilariño iba a mostrar sus destrezas analíticas: ya fuera identificando los grupos rítmicos de distinta cantidad silábica para sus combinaciones y reiteraciones, como marcando dentro de ellos las vocales, tónicas o átonas, y cartografiando en la masa vocálica ordenamientos, simetrías, disrupciones.

Es lícito preguntarse cual sería el resultado de aplicar este método de análisis a la propia poesía de Idea Vilariño; se trataría de ver si es en las regularidades rítmicas (¿racionales, intuitivas?) que se sostiene el arte de su poesía. Sin el énfasis que Idea puso en sus trabajos sobre grupos simétricos y masas sonoras, dos ensayos ya imprescindibles abren el campo para esa tarea. Martha Canfield lo hizo en 1988 en "La proyección cósmica: Idea Vilariño", incluido en su libro Configuración del arquetipo. En él dedicó un capítulo a "El tejido fónico" de la poesía de Idea, revelando "el recurso notable al fonosimbolismo y el uso constante de casi todas las figuras retóricas de repetición". Asimismo, dio cuenta de una forma de "balbuceo", de un ir buscando la palabra justa en el conjunto indeterminado o corrompido del lenguaje, que rodeaba con angustia la palabra-verdad y que, no pocas veces, devenía silencio (Canfield, 1988: 75-81). El otro trabajo, más reciente, de 2020, es el de Gustavo Lespada, que porta el piuserviano título de "La puerta secreta (ritmo y significación en la poesía de Idea Vilariño)". Lespada obedece, de la lección de Idea, la escucha del ritmo, respiración de las palabras que provocan el fantasma de la voz. Las estructuras de reiteración llevan al extremo de machacar, insistir, hasta desplazar al signo lingüístico de su lugar semántico: Lespada toma de Noé Jitrik el concepto de semiosis de la incesancia para explicar la enajenación del signo del cómodo sistema referencial (Lespada, 2020: 51). 


\section{Mario Benedetti: clara, sencilla, poesía}

El caso de Benedetti no es menos interesante. Su lectura temprana de Baldomero Fernández Moreno, que oficia de excusa de este trabajo, parece, en sus distintas versiones, precisa en su lugar, un poco menos en su momento. Benedetti, en los muchos reportajes que le hicieron, remontó el conocimiento de Fernández Moreno a su muy juvenil estadía en Buenos Aires. En una escena mítica, iniciática, un muchacho uruguayo que se ha ido a trabajar a la capital argentina, en los intersticios de su agobiante jornada laboral o tal vez un domingo solitario, lee con fruición un libro hojeado y comprado en una mesa de saldos de alguna librería céntrica. El lugar es la plaza San Martín; el libro, alguno de los muchos publicados por Fernández Moreno; el momento, los imprecisos años en los que Benedetti, muy joven pero seguramente no menor de edad, trabajó en la ciudad porteña para Raumsol, fundador del movimiento logosófico en el Río de la Plata. El resultado de la lectura estaba dicho o pensado más o menos de esta forma: "lo que estoy leyendo no por ser claro y sencillo deja de ser poesía. Esto quiero hacer yo". 4

En una hermosa intervención, "Mario Benedetti y mi generación", realizada en el Congreso Internacional que le dedicó a Benedetti la Universidad de Alicante en 1997, y que puede leerse en Inventario cómplice, Jorge Ruffinelli no dejó de plantearse la oscura perplejidad que siempre le provocaron esos años juveniles que quedaron en la penumbra. En su reflexión testimonial, Ruffinelli buscó entender y asimilar esa experiencia primera a la vida del escritor. Lo curioso, entonces, fue que, en medio de esa mística un poco burocrática que supuso la participación del joven Benedetti en la Escuela Logosófica, se puso a germinar una extraña semilla que, de manera pretenciosa, podríamos ser reconocida como una estética de la poesía. Impertinente forzar relaciones entre una cosa y otra. Sí se podría afirmar que esa semilla del sencillismo, anterior a 1940, tardó en mostrar su resultado.

Benedetti publicó su primer libro de poesía, La víspera indeleble, en 1945 . Su lectura me deja desconcertado y casi mudo: no consigo entenderlo, adivinar sus búsquedas. Es obvio que a Benedetti no le sucedió lo mismo, ${ }^{5}$ y que tampoco fue por eso que decidió olvidar este libro, no reeditarlo ni incluirlo más tarde en la summa poética que llamó Inventario. Seguramente veía en él algo que yo no veo y que en algún momento dejó de agradarle, pero sobre el punto no encuentro ninguna afirmación clara, si no es esta: en 1945 la lección posible de la poesía sencilla de Fernández Moreno todavía no se había revelado; en 1963, cuando decidió reunir sus libros de poesía en la primera edición del Inventario aquella víspera se había borrado.

4 En esos términos se lo contó a Martha Canfield en un reportaje que, traducido al italiano: "La poesia, la politica, l'amore: una conversación con Mario Benedetti”, la crítica incluyó en Inventario, Poesie 1948-200o, Florencia, Le lettere, 2001: 281-299. En él se refirió a la poesía hermética que se escribía en el Río de la Plata de la que él disfrutaba como lector pero a la que había decidido no seguir como poeta. Precisó que en Buenos Aires había encontrado una antología de Baldomero Fernández Moreno publicada por Espasa Calpe en su colección Austral: la había comprado y leído toda en la plaza San Martín. Y entonces se había dicho: "Este es un tipo de poesía que yo puedo hacer; que es clara, que es sencilla y que es poesía” (tomado de Canfield, 2013: 332-354). Sobre este episodio, como se dijo, puede haber otras versiones y tal vez se deberían ajustar los detalles de sus testimonios. La Antología (1915-1940) fue publicada por Espasa Calpe en 1941. Hortensia Campanella en su biografía asegura que, a principios de 1940, Benedetti ya estaba de regreso en Montevideo. Seguiría vinculado a la Escuela Logosófica y a la publicación de su revista, pero ya no en Buenos Aires. Campanella agrega que el 20 de junio de 1940 se produjo su ingreso a la función pública en la Contaduría General de la Nación (2008: 39).

5 "Las oscuridades que halla el lector fueron claridades para el autor, salvo que este sea un oscurecedor deliberado" escribe Benedetti en su temprano artículo "Hermetismo y claridad en la literatura", Marcha, 8 de julio de 1949. Creo que es lícito aplicar la idea a lo que me sucede: presumo que no hay oscurecimiento deliberado, pero no acierto a vislumbrar el sentido. Algo vio Juan Cunha, pero era Juan Cunha, cuando dicen que le dijo que era el mal libro de un buen poeta. 
En relación a los tiempos de llegada o de florecimiento del fenómeno Benedetti querría razonar con cautela. Se dice que Poemas de la oficina (1956) tuvo rapidísima acogida y que sus ediciones se agotaron y se sucedieron en poco tiempo. No había sucedido lo mismo con el anterior Solo mientras tanto (1950). ¿Tuvieron los dos libros posteriores a Poemas de la oficina: Poemas del hoyporhoy y Noción de patria, la misma fortuna que el emblemático librito de 1956? Tiendo a pensar, dejándome llevar por el entrañable artículo de Alicia Migdal "La novedad de lo cotidiano en la poesía de Mario Benedetti" (1997), que el "efecto Benedetti", cuyas primicias habían sido los oficinescos poemas de los años 1950, se hizo pleno en la década siguiente; entonces el impacto ya no lo provocaría cada libro sino el conjunto de ellos reunidos. A la primera edición del Inventario de 1963 que reunía cuatro libros, siguieron, en esa década, tres más en 1965, 1967 y 1970, cada una ampliada por los libros nuevos que iban apareciendo. En ocasión de su artículo, Migdal releyó la segunda edición, aquella que la remitía a sus años de liceo. Tal vez pudo volver a comprobar que esos cinco libros, reunidos, se dejaban leer en un movimiento que nos llevaba de unos a otros; se podía saltar desde la interrogación existencial de "Ausencia de Dios" al recitadísimo "Corazón coraza", pasando por la grisura burocrática de "Ángelus", el lamento solitario en la enajenadora Nueva York de "Cumpleaños en Manhattan" o la ironía un poco ingenua de "Los pitucos"; todo ello con la inminencia y a la espera del augural "Todos conspiramos" y de la elegía luminosa de "Consternados, rabiosos".

En un trabajo reciente me pregunté, sin responder plenamente, de dónde salía el Benedetti de los poemas de la oficina (Brando, 2020). No terminaban de convencerme, y aún ahora no lo hacen, las referencias que tradicionalmente se habían manejado como fuentes posibles. Los Cuentos de la oficina de Roberto Mariani (1925), como toda la literatura de Boedo o la narrativa de Arlt, cargaron con un componente ruso que, a la altura de las vanguardias argentinas, se cruzaba con la deformación y el delirio expresionistas. Eso estaba lejos de la estética benedettiana. Las otras influencias que se señalaron fueron la del sencillismo de Fernández Moreno y la de la antipoesía de Parra, tan cercana en la fecha de publicación. El lirismo antipoético de Parra también tenía un componente del vanguardismo histórico, de índole surreal, que no afectaba a la poesía de Benedetti. Incluso podría quedar la duda sobre cuánto conocía Benedetti, a mediados de los años 1950, la poesía de Parra. En el ensayo que escribió sobre el poeta chileno en 1963, para la primera entrega de la segunda época de la revista Número (que luego recogió en libro), confesó que no había podido leer el primer libro de Parra, Cancionero sin nombre de 1937 (justamente una poesía de la claridad según voluntad de Parra, contra la oscuridad surreal del Neruda residenciario) y recordó el trabajo que le había dado conseguir un ejemplar de la segunda edición de Poemas y antipoemas, que finalmente había encontrado en una librería de saldos en Nueva York, esto es, en 1959 durante los meses de estadía en esa ciudad. Pero eso no es concluyente sobre su acercamiento a la antipoesía de Parra, pues sus más estrechos compañeros de Número, Emir Rodríguez Monegal e Idea Vilariño, habían leído el libro de 1954. Rodríguez Monegal, recién venido de Chile, había escrito en Marcha antes de la salida del libro, adelantando algunos inéditos; e Idea Vilariño lo había comentado, con acritud, al año siguiente. Era muy poco probable que Benedetti no lo hubiese pedido prestado para atender con el mismo interés que sus amigos la novedad que presentaba ese libro del chileno. Respecto al sencillismo de Fernández Moreno, tenemos la confesión del conocimiento temprano de la obra del poeta argentino y del efecto que esa estética produjo en el jovencísimo lector. Dos dudas, sin embargo, se ciernen: una ya planteada sobre qué pasó durante el no breve tránsito entre ese deslumbramiento de fines de los años 1930 y la poesía de la oficina de 1956; la segunda duda es cuánto de aquello que daba forma a la poesía de Fernández Moreno migró a la de Benedetti.

Hay algo que me sigue interrogando desde los Poemas de la oficina: no parecen surgidos del mero sencillismo pero tampoco resultan solamente inspirados por la línea 
de la poesía hispanoamericana que José Emilio Pacheco llamó "la otra vanguardia" (Pacheco, 1979). Roberto Fernández Retamar remontó el prosaísmo a Ramón de Campoamor (Fernández Retamar, 1995). En esa genealogía podrían revistar las Gotas amargas de Asunción Silva, la "Epístola a la Sra. de Lugones" de Darío, Ramón López Velarde, el colombiano Luis Carlos López, el Movimiento de Vanguardia nicaragüense (José Coronel Urtecho, Pablo Antonio Cuadra, Joaquín Pasos), Salvador Novo y Salomón de la Selva que entroncaban con ciertas derivas de la poesía angloamericana. La poesía conversacional que vendría más tarde, a partir de 1960, con Ernesto Cardenal, Fernández Retamar, Roque Dalton, iba a tener un mejor compañero en el Benedetti que empezamos a leer después de los Poemas de la oficina: Poemas del hoyporhoy, Noción de patria, etc.

En cuanto a la proximidad a Baldomero Fernández Moreno, permítaseme una apresurada reflexión a partir del repaso de unos pocos poemas. Benedetti comenzó su ensayo "Baldomero Fernández Moreno o el rescate de la claridad" recordando una muy repetida afirmación de Borges según la cual Baldomero habría tenido una "percepción genial del mundo exterior" (1994: 32). Borges reconocía en Fernández Moreno algo que para su tiempo (¿o para Borges?) parecía revolucionario: haber mirado a su alrededor. Esa actitud había impreso la necesidad de una dicción sencilla que remitía al mundo mirado, a la experiencia de esa percepción. Obviamente, Machado podía estar en el origen, pero lo acompañaban en su tierra natal el fervor del primer Borges por la ciudad, si se pudieran excusar las mediaciones de la metáfora y a veces de un diccionario de argentinismos; Raúl González Tuñón y el grupo de Boedo (Mariani, Olivari), si fuera factible desagregar la misión social; y los mitos populares de Evaristo Carriego. En Baldomero se sumaba la nostalgia, de ahí que su hijo César diera comienzo al capítulo sobre sencillismo de su libro La realidady los papeles desarmando la palabra en sus componentes etimológicos griegos: nostos, "regreso"; algos, "dolor". "La nostalgia es el dolor de estar separado de cierto lugar al que se desea regresar, sea por haberse nacido en él o por tener radicada en él su sangre, su origen" (1967: 103). César nos recordaba la peripecia tan peculiar de su padre: nacido en la Argentina, vivió en España desde los 6 hasta los 13 años y luego volvió a su país natal para itinerar poéticamente, a lo largo de su vida, entre los dos orígenes. Tal fue así que llamaría a su prosa autobiográfica La patria desconocida.

En su ensayo, Benedetti hizo una observación sutil sobre el recurrido y brevísimo poema "Paisaje" de Fernández Moreno: "Ocre y abierto en huellas, el camino/ separa opacamente los sembrados.../ Lejos, la margarita de un molino" (1994: 37-38). Ese molino visto a lo lejos, sin otra aparente presencia que la visual, abre, sin embargo, el proceso de un recuerdo a través de una comparación sorda: asoman allí los molinos españoles que son paisaje real y de cultura que Baldomero habría transportado de su niñez en España. Lo mismo podría decirse, agregaba Benedetti, del más recitado poema de Baldomero "Setenta balcones y ninguna flor". El campo en el primer caso, la ciudad en el segundo, despiertan la comparación y trazan el puente ensoñado entre los lugares para abrir la indecisa, "desconocida patria" de su poesía. Si pasamos a la larga, larguísima (ciento veintiocho tercetos, para ser exactos; perfectamente encadenados: aba/bcb/cdc etc., para ser justos) y tan elogiada por Benedetti "Epístola de un verano" asistimos a la morosa observación de la hora de la siesta en Chascomús, vista por el poeta semidesnudo, meciéndose en una silla al amparo dulzón de una glicina. Pasan en él imágenes, se cuelan recuerdos, mucho cabe en sus derivaciones que incluyen Buenos Aires y la lejana España, todo ello convergiendo hacia la vida, en la actitud del que, como escribió con indisimulado fastidio Idea Vilariño, quiso ser poeta.

Si de Baldomero saltáramos a Benedetti tendríamos en "Elegir mi paisaje" de Solo mientras tanto un "mi paisaje/ de otoño desolado" que elige una calle en la que está, a la que mira y en la que se reflejan, a modo de delirio, imágenes visionarias: 
acumulaciones caóticas parecen eco del Neruda residenciario ("Aquí hay pájaros, lluvia, alguna muerte,/ hojas secas, bocinas y nombres desolados") y algún zeugma: "mientras la humedad trae lamentos y moscas", irrumpe con resonancias tal vez parrianas. Hay un pasado que revive en esa calle con balcones, asordinado homenaje a Baldomero, "de la que sé con estricta nostalgia/ el número y el nombre de sus setenta árboles". El paso siguiente, los poemas de la oficina, fue más que paso un salto sustancial: la voz poética ya no identificaba al que cantaba mirando el acontecer sino que encarnaba a la criatura sufriente del mundo que vivía. Las cosas miradas y vulgares: oficinas, papel carbónico, sueldos y aguinaldos, dactilografía, se convertían, como dice Alicia Migdal, en la materia prima de un género elitista por excelencia (Migdal, 1997: 43-44). Pero la clave tal vez no estuviese allí sino en el punto de vista, eso de ver al personaje en el poema, advertir que podría ser yo, sentirlo sentir la desolación y la impotencia, oírlo decir el fracaso. Esa encarnación, que presumo que fue el mayor hallazgo de esta poesía, lo distanció del sencillismo descriptivo/subjetivo al tiempo que lo diferenció de la posterior poesía conversacional que pondría cadencia a la peripecia del ser en una historia mayor. En la oficina la historia era menor, se trataba de un presente demoledor que absorbía el pasado y aniquilaba el futuro: "Quién me iba a decir que el destino era esto".

Desfilaban, entonces, todas las lacras, impurezas y tristezas del hombre resumidas en su amor burocrático, en su vida estéril plena de insatisfacciones e incapaz de recuperar el Montevideo verde de la infancia con tranvía que pretendía colarse entre las líneas/versos de la carta comercial dactilografiada ("Dactilógrafo"). Ese personaje o esos personajes, que podían ser el mismo con matices, aportaban la singularidad a ese conjunto de poemas. El lector pero también el poeta se confundían con él/ellos; se ponía en práctica aquello que Parra diría años después: "los poetas bajaron del Olimpo" no solo porque miraban el mundo vulgar sino porque ellos mismos eran habitantes vulgares de ese mundo. Creo que la poesía posterior, que fue diseñando otros recursos de comunicación, ya no se ajustó exactamente a este.

\section{Final trunco}

El libro sobre Baldomero Fernández Moreno, finalmente, no llegó a publicarse en la colección Archivos de la Unesco. Algunas de las colaboraciones habían sido entregadas pero desavenencias, no sé exactamente de qué tipo (tengo solo versiones orales), frustraron la continuación del trabajo. La recopiladora de los ensayos de Idea Vilariño, Ana Inés Larre Borges, que incluyó en De la poesía y los poetas el trabajo inédito de Idea Vilariño, anotó al pie de página que se trató de discrepancias entre Benedetti y Segala. No fue el único libro proyectado para Archivos que no llegó a ver la luz; por allí quedó un Felisberto Hernández ya terminado, un Florencio Sánchez no sé en qué estado, un proyecto sobre Isidore Ducasse que creo no pasó del planteo inicial, un volumen sobre las poetas uruguayas Delmira, María Eugenia y Juana que iba a estar al cuidado de Idea Vilariño (carta de Benedetti del 3 de noviembre de 1985). El trabajo de Idea sobre Baldomero, entregado a principios de 1985, durmió en su archivo hasta su inclusión en la recopilación de 2018. Era, como se ha dicho a lo largo de este artículo, un empeño a contrapelo, hecho, paradójicamente, con dedicación, seriedad y desgano. Eso no impidió que, apenas entregado, Benedetti lo elogiara a pesar de los reparos que Idea había puesto a la poesía de Baldomero. Ambos, Benedetti e Idea, podían sentirse inhibidos por la cercanía del hijo, César, que también iba a colaborar en el libro. Idea no intentó el análisis formal que le sugería Benedetti y apenas hizo alguna consideración prosódica con la especificación de los tipos de versos que Fernández Moreno desplegó. A la poca afinidad que sentía por la poesía se agregaba cierto fastidio con el personaje que no consiguió disimular del todo. Incluso, el ensayo resultó breve de acuerdo con lo estipulado por las pautas escritas para la colección. 
Respecto a Benedetti, no tengo la certeza de que el trabajo incluido en el libro Poetas de cercanías sea la reproducción del que escribió para aquella oportunidad. Hace pensar que sí la fecha con que se cierra, 1986. Pero la Nota de presentación del libro no lo aclara y bien pudo ser resultado de uno de los cursos de verano que daba en esos años en universidades españolas. Contra lo esperado, Benedetti puso énfasis en el Baldomero tardío, otoñal, y no solo en el primer poeta, el sencillista. Descubrió en los sonetos de Penumbra y en los inéditos, que César le permitió consultar, un poeta menos epitelial, más intenso, quizá en mejor sintonía con la poesía que Benedetti había comenzado a escribir en los años ochenta. Consta en la correspondencia que Benedetti pudo consultar Penumbra en el ejemplar de César y que le sacó dos fotocopias, una para él y otra para Idea. Benedetti confiaba en que la lectura de esta poesía final podía mejorar la visión de su amiga. Idea Vilariño atendió a los sonetos de Baldomero y opinó que muchos eran correctos, algunos buenos, nunca "magníficos sonetos" como dice que había sido escrito. Cerró su trabajo con una referencia a Penumbra: "Si estos poemas son más poesía no es porque sean mejores sonetos sino por la mayor intensidad que los obliga; por la dolorosa concentración del autor en sí mismo, en las interrogantes sobre lo que fue su vida; por el sentimiento penoso de su menoscabo, de su soledad, de su tránsito; por la espera de la muerte" (Vilariño, 2018: 313).

En el extraordinario trabajo sobre Julio Herrera y Reissig con el que introdujo la Poesía completa y prosa selecta en la edición venezolana de Ayacucho, luego de esbozar en unas pocas líneas la corta vida de su querido Julio, Idea Vilariño concluyó: "Pero nadie es tan sencillo" (2018: 4). Nadie es lo que parece ser y no hay biografía que consiga revelar todo. Idea le confesó a Elena Poniatowska (Vilariño, 2007: 131) que podría no haber sido muchas de las cosas que fue: lo único que no habría podido dejar de ser era poeta. Benedetti expresó, con mayor pudor, la prioridad de la poesía. Volver a Idea Vilariño y Mario Benedetti, juntos o separados, es volver a un cúmulo de peripecias, de vidas atravesadas por mil tareas. Pero nadie es tan sencillo. No se explican esas vidas por la acumulación de experiencias. En el centro de ellas sigue estando la poesía, condensándolas, explicándolas a su manera. 


\section{Q Bibliografía}

»Archivo Literario de la Biblioteca Nacional de Uruguay, Colección Idea Vilariño, Correspondencia.

"Bajter, I. (2014). El ritmo y otros aspectos de Idea Vilariño en la crítica dura. En Idea, Revista de la Biblioteca Nacional, 9: 75-105. Montevideo.

» Benedetti, M. (2014 [1949]). Hermetismo y claridad en la poesía. Marcha, 8 de julio; recogido en Notas perdidas, tomo 1. Rocca, P. (invest., plan gral. y pról.). Montevideo: Universidad de la República.

»Benedetti, M. (1950). Solo mientras tanto. Montevideo: Número.

»Benedetti, M. (1956). Poemas de la oficina. Montevideo: Número.

» Benedetti, M. (1967 [1963]). Parra descubre su realidad. Número, $2^{\mathrm{a}}$ época, año 1, № 1, abril-junio; recogido en Letras del continente mestizo. Montevideo: Arca.

»Benedetti, M. (1972). Idea Vilariño: el amor y la muerte, esas certezas. En Los poetas comunicantes, pp. 251-263. Montevideo: Biblioteca de Marcha.

» Benedetti, M. (1994). Baldomero Fernández Moreno o el rescate de la claridad. En Poetas de cercanías. Montevideo: Cal y Canto.

»Benedetti, M. (2001). Inventario, Poesie 1948-2000. Florencia: Le lettere.

»Brando, O. (2020). Introducción B/V. [Sic]. Revista arbitrada de la Asociación de Profesores de Literatura del Uruguay, no 26, pp. 5-15.

"Campanella, H. (2008). Mario Benedetti. Un mito discretísimo. Montevideo: Seix Barral.

»Canfield, M. (1988). La proyección cósmica: Idea Vilariño. En Configuración del arquetipo. Florencia: Opuslibri Universitá degli studi di Firenze.

"Canfield, M. (2013). Mario Benedetti: sencilla complejidad de un poeta entrañable. Cuadernos de literatura, vol. XVII, nº 33, pp. 332-354.

»Fernández Moreno, B. (1987). Poesía y prosa. Lafforgue, J. (pról.). Buenos Aires, Cedal.

"Fernández Moreno, C. (1967). La realidad y los papeles. Madrid, Aguilar.

»Fernández Retamar, R. (1995). Antipoesía y poesía conversacional en Hispanoamérica. En Para el perfil definitivo del hombre. La Habana, Letras Cubanas.

»Lespada, G. (2020). La puerta secreta (ritmo y significación en la poesía de Idea Vilariño). Sic, 26, septiembre. Montevideo.

» Lotman, Y. (1978). La estructura del texto artístico. Madrid: Itsmo.

»Mariani, R. (1925). Cuentos de la oficina. Buenos Aires: Claridad.

»Migdal, A. (1997). La novedad de lo cotidiano en la poesía de Mario Benedetti. Lago, S. y Torres, A. (comps.). Actas de las jornadas de homenaje a Mario Benedetti. Montevideo: Universidad de la República.

»Pacheco, J. E. (1979). Nota sobre la otra vanguardia. Revista Iberoamericana, no 106-107, pp. 327-334.

»Revista de la Biblioteca Nacional, Idea, 9 (2014). Rescate. Correspondencia Idea 
Vilariño-Ángel Rama acerca de Julio Herrera y Reissig, pp. 223-227. Montevideo.

"Ruffinelli, J. (1999). Mario Benedetti y mi generación. En Rovira, C.; Alemany, R. y Mataix, J. C. Inventario cómplice. Alicante: Universidad.

»Vilariño, I. (1947). Los Nocturnos de Parra del Riego. Clinamen, № 1, marzo-abril. Montevideo.

"Vilariño, I. (1951). Grupos simétricos en la poesía de Antonio Machado. Número, año 3, 15-16-17, julio-diciembre. Montevideo.

»Vilariño, I. (1958). Grupos simétricos en poesía. Montevideo: F. H. y C. Universidad de la República.

"Vilariño, I. (1986). La masa sonora del poema. Montevideo, Arca; (s/f ¿200o?). Montevideo. Al Margen. (2016). Bajter. I. (ed. definitiva). Montevideo: Biblioteca Nacional de Uruguay.

»Vilariño, I. (1988). Conocimiento de Darío. Montevideo, Arca.

»Vilariño, I. (2007). Idea Vilariño: La vida escrita. Montevideo: Cal y Canto/Academia Nacional de Letras.

»Vilariño, I. (2013). Diario de juventud. Larre Borges, A. I. y Alicia Torres, A. (eds.). Montevideo: Cal y Canto.

"Vilariño, I. (2016). La masa sonora del poema. Bajter, I. (ed.). Montevideo: Biblioteca Nacional.

»Vilariño, I. (2018). De la poesía y los poetas (textos criticos). Larre Borges, A. I. (recop. y pról.). Montevideo, Biblioteca Artigas, Colección Clásicos Uruguayos Vol. 208, Ministerio de Educación y Cultura.

»Vilariño, I. y Rama, Á. (2014). Rescate. Correspondencia Idea Vilariño-Ángel Rama. Revista de la Biblioteca Nacional, 9, Idea. 
